\title{
Primary mucinous carcinoma of the skin: a case of metastasis after 10 years of disease-free interval
}

\author{
M. Miyasaka $\cdot$ R. Tanaka $\cdot$ K. Hirabayashi $\cdot$ \\ A. Yamazaki $\cdot$ H. Shinohara $\cdot$ H. Taira $\cdot$ T. Akamatsu
}

Received: 30 September 2008 / Accepted: 14 October 2008 / Published online: 5 November 2008

(C) The Author(s) 2008. This article is published with open access at Springerlink.com

\begin{abstract}
Primary mucinous carcinoma of the skin (MCS) is a rare neoplasm. Clinically, it has a high local recurrence rate, but it is known to be a slow-growing benign tumor with a rare incidence of distant metastases. We present a case of primary MCS on the jaw that underwent tumor resection twice and was disease-free for 10 years after the second surgery. The patient had no evidence of local recurrence and distant metastasis until his 11 th year followup. At that time, he was diagnosed with lung and bone metastasis and died 3 years after this. To our knowledge, this is the first case of MCS that presented with metastasis with more than 10-year disease-free interval. Since MCS is a slow-growing asymptomatic tumor, distant metastasis is difficult to diagnose without detailed radiological examination. We believe that computed tomography and resonance imaging should be performed for early diagnosis of metastasis even for cases with long-term disease-free interval, especially cases of local recurrence.
\end{abstract}

Keywords Mucinous carcinoma · Skin · Metastasis .

Recurrence $\cdot$ Disease-free interval

M. Miyasaka $(\bowtie) \cdot$ R. Tanaka $\cdot$ A. Yamazaki $\cdot$ H. Shinohara $\cdot$

H. Taira $\cdot$ T. Akamatsu

Department of Plastic and Reconstructive Surgery,

School of Medicine, Tokai University,

143 Shimokasuya Isehara-shi,

Hiratsuka, Kanagawa 259-1193, Japan

e-mail: miyasaka@is.icc.u-tokai.ac.jp

K. Hirabayashi

Department of Pathology, School of Medicine, Tokai University,

Hiratsuka, Kanagawa, Japan

\section{Introduction}

Primary mucinous carcinoma of the skin (MCS) is a rare neoplasm of sweat gland origin [1, 2]. Breiting et al. [2] recently reported that approximately 200 cases have been documented until now, and the mean annual agestandardized incidence of MCS during 1978 to 2003 was 0.07 per million person-years. MCS most commonly occurs on the eyelids, scalp, and other sites on the head and neck [3,4]. It is characterized clinically as asymptomatic, slow-growing nodules, cysts, or ulcers. Although it is a benign tumor, an adequate amount of normal skin excision is recommended due to the high rate of local recurrence. However, hematologic or lymphatic spread is uncommon [5]. Snow and Reizner reported a 30\% local recurrence rate and a $2.7 \%$ rate of distant metastases [6, 7]. Accordingly, death from MCS is rare, and it usually has a favorable prognosis.

We present a rare case of MCS of the jaw, which was resected twice and had a disease-free interval for more than 10 years but suddenly presented with multiple bone and lung metastases. We believe that this is the first case reported of death due to distant metastasis of MCS with a disease-free interval of more than 10 years.

\section{Case report}

A 39-year-old Japanese male presented with a 3 months history of a skin tumor on the left side of the jaw. Past medical history revealed lung tuberculosis at age 20 years old. Physical examination showed a dome-shaped, slightly erythematous nodule measuring approximately $2 \mathrm{~cm}$ in diameter (Fig. 1). Preoperative examination revealed no lymph node or distant metastasis. Punch biopsy was 


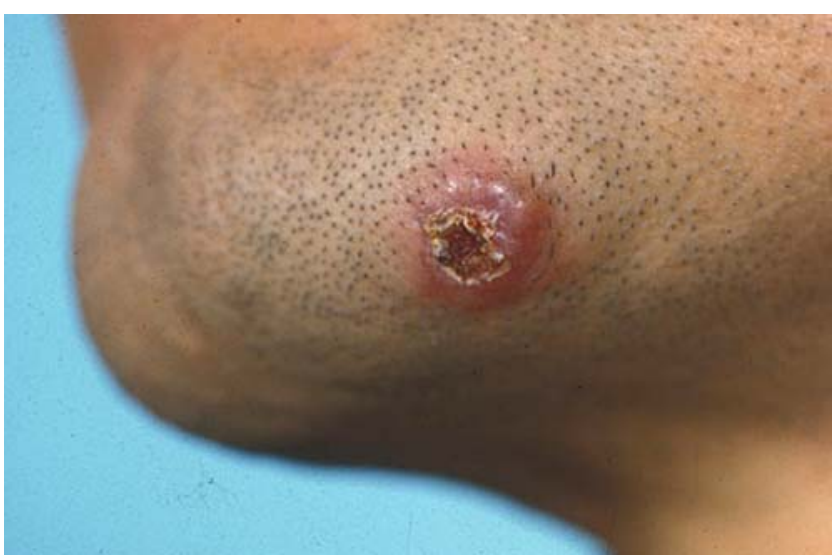

Fig. 1 A 39-year-old Asian man presented with a 3-month history of a dome-shaped, slightly erythematous nodule measuring approximately $2 \mathrm{~cm}$ on the left side of the jaw

performed, and it was diagnosed as mucinous adenocarcinoma of the skin.

The tumor was excised with 5-mm surgical margin and was reconstructed with local rotational flap. The definitive histopathology showed small cellular nests of adenocarcinoma lying in pools of extracellular mucin that were separated by fibrocollagenous septae without involvement of underlying muscle. (Figure 2a,b) The immunohistochemical staining revealed that the tumor cells were positive for CK7, epithelioid membrane antigen (EMA), MUC1, MUC2, estrogen receptor (ER), and progesterone receptor (PR).

The patient again noticed a small tumor on the left side of the jaw in the area of the previous operation site 2 years after the primary operation. However, the patient had chosen not to be examined by a physician and left it alone for 4 years. Because of the rapid growth of the tumor, the patient visited our clinic. At this point, the tumor measured approximately $6 \mathrm{~cm}$ in diameter (Fig. 3a). Preoperative examination revealed invasion of the mandible and one left neck lymph node metastasis. The lesion was excised with at least $1-\mathrm{cm}$ border of normal skin including the mandible (Fig. 4). A left radical neck dissection was performed, and the mandible was reconstructed with a free scapula flap. The definitive pathology revealed MCS recurrence with no residual tumor cells in the excised normal skin area. One of 20 regional lymph nodes contained metastasis. Postoperatively, the patient was free of tumor and was followed up by the physician in charge every 3 months for 5 years and every 6 months for the next 5 years. The patient was disease-free for ten consecutive years on physical examination, chest $\mathrm{X}$-ray, neck echogram, and ordinary blood test. Although the patient did not have any symptoms, the chest X-ray at the 11th year follow-up revealed multiple lung metastases (Fig. 5a,b). Additional chest computed tomography (CT), magnetic resonance imaging (MRI), and RI showed cervical

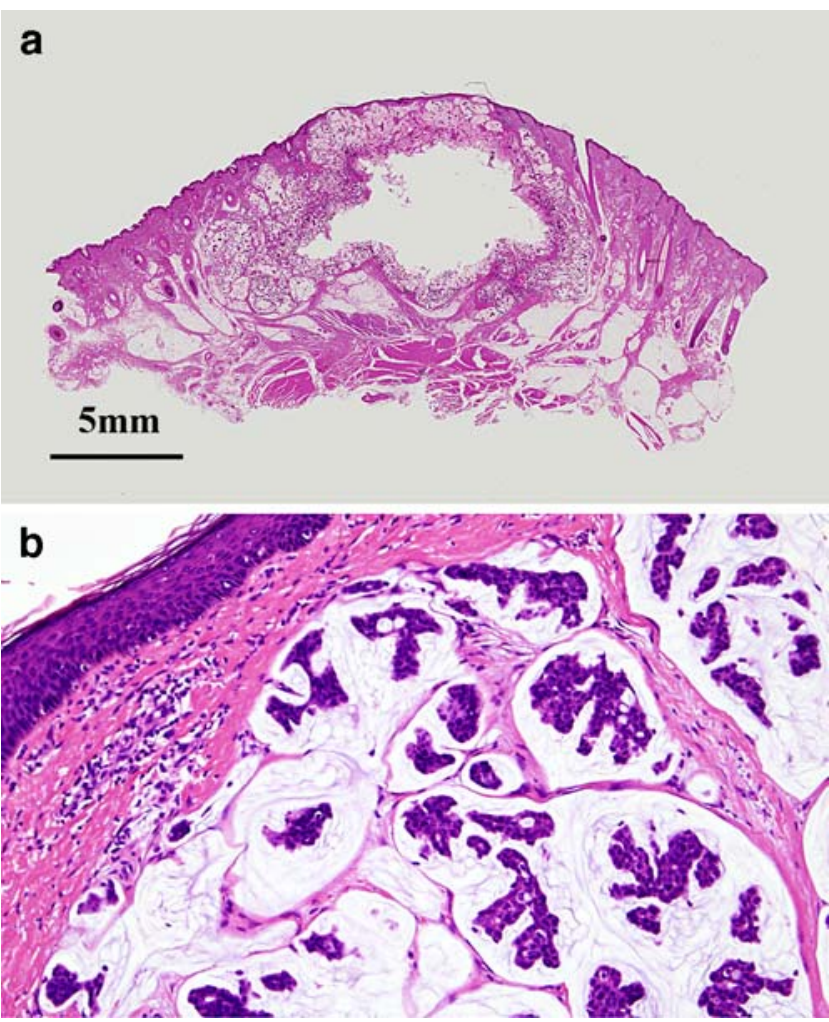

Fig. 2 a,b The definitive histopathology showed small cellular nests of adenocarcinoma lying in pools of extracellular mucin that were separated by fibrocollagenous septae without involvement of underlying muscle. There was no evidence of lymphatic invasion

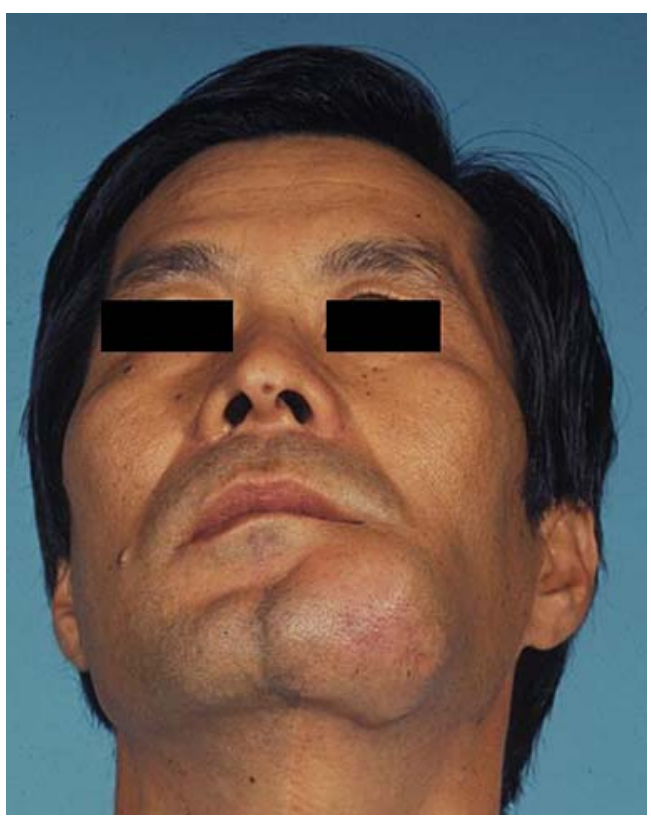

Fig. 3 The patient had dropped out of postoperative follow-up and had visited the clinic 4 years after the surgery with a tumor measuring approximately $6 \mathrm{~cm}$ on the left side of the jaw arising in a previously operated site 


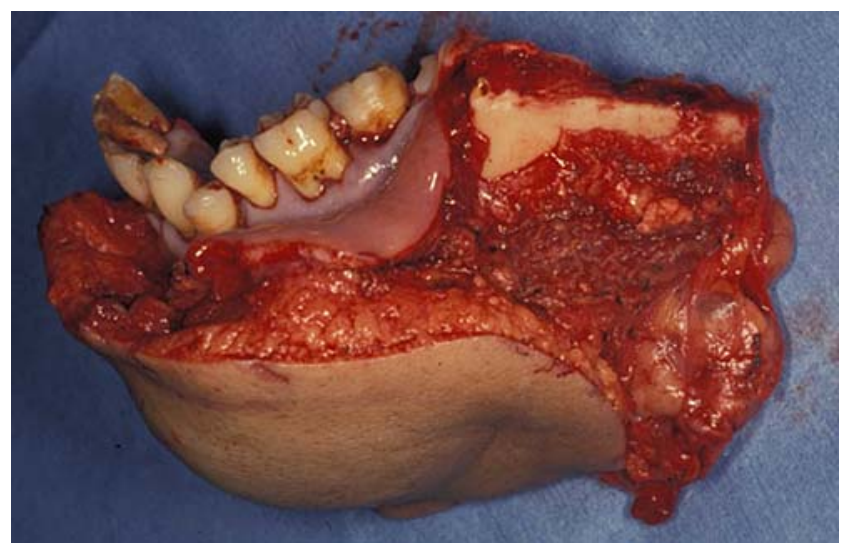

Fig. 4 Preoperative examination revealed mandible invasion with the tumor and one left neck lymph node metastasis. Therefore, the tumor was excised with more than $1 \mathrm{~cm}$ of surgical margin with a partial mandible resection and a left radical neck dissection

vertebrate (Th5) tumor, and biopsy revealed metastasis of MCS. The patient received radiotherapy for pain control and died 3 year after the diagnosis of metastasis.

\section{Discussion}

Primary MCS is rare, but there have been sporadic cases reported since it was first described by Lennox et al. in 1952 [8] and later reviewed by Mendoza and Helwing in 1971 [9]. MCS is usually present in middle aged or older persons and is more frequent in men than in women. Most mucinous tumors involving the skin are a result of metastases from various sites, including breast, upper airways, gastrointestinal tract, salivary and lacrimal glands and paranasal sinuses, and urinary tact [10]. It is important to distinguish between the metastatic tumor and MCS because MCS is generally more benign and has a very good prognosis compared to metastatic tumor of the skin. Differential diagnosis of the two is made by histological and systematic evaluation [11, 12]. Histologically, MCS is described as a tumor consisting of islands of epithelial cells floating in pools of extracellular mucin separated by fibrocollagenous septa [13]. It is shown to express certain immunohistochemical markers such as CK7 [3], EMA [3], and ER and PR [14-16] different from metastatic tumor of the skin.

MCS is typically slow growing with long duration of lesions prior to biopsy; this can be as long as 20 years [17, 18]. However, it has a significant incidence of local recurrences, as high as $36-45 \%$ [17]. Direct invasion into skeletal muscle, periosteum, bone, and dura has been reported $[16,17]$. Warycha et al. recently reported a case of MCS with direct histopathological evidence of lymphatic invasion. Distant metastasis is extremely rare, and there have been only two recorded cases in the past $[19,20]$. Our case also showed local recurrence with direct bone invasion and lymph node metastasis even after excision of the tumor with a $5-\mathrm{mm}$ surgical margin, which had been pathologically estimated as clear. Treatment of MCS is primarily
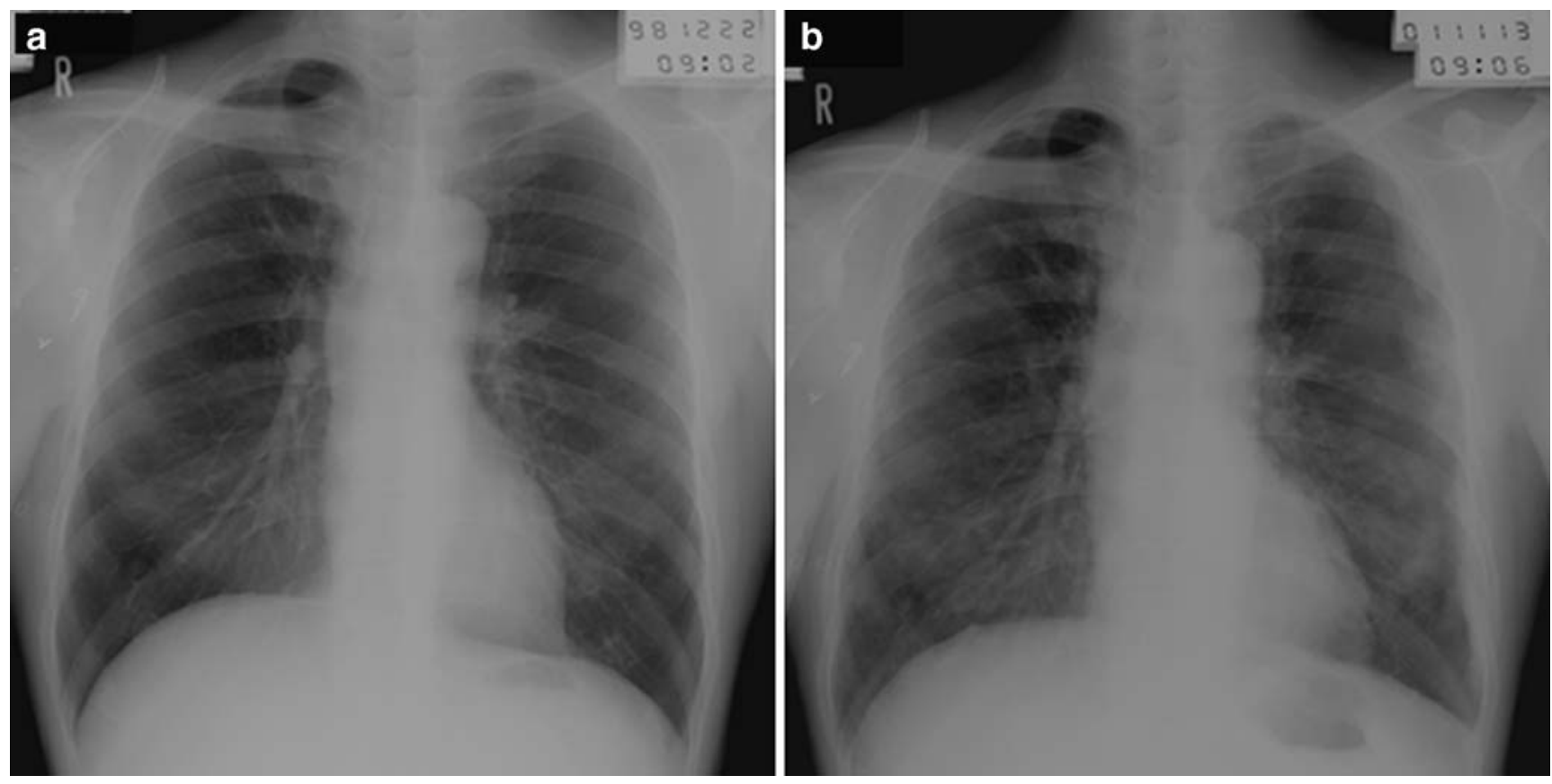

Fig. 5 a The chest X-ray performed at the 10-year follow-up did not show any obvious sign of lung metastasis. b However, shadowing of multiple lung metastases was evident at the 11-year follow-up 
surgical with a wide local excision and clear margins. However, the definition of wide excision is not clearly documented. In our case, a 5-mm clear margin was not an adequate amount of excision. Some authors recommend the use of Moh's micrographic surgery in the head and neck area, given the risk of local recurrence and distant metastasis due to incomplete removal $[13,16]$. Unfortunately, Moh's surgery cannot be easily done in all hospitals. Martinez and Young [21] documented that the average surgical margin in cases reported was $12.5 \mathrm{~mm}$ in the least dimension. We speculate from our case and other reports by various authors that the surgical margin should be more than $1 \mathrm{~cm}$ together with detailed pathological examination of lymphatic invasion.

Since local recurrence is a frequent complication, our patient was followed up at three monthly intervals for the first 5 years and at six monthly intervals for the next 5 years. Despite the fact that the patient was disease-free for more than 10 years after the second surgery with negative chest $\mathrm{X}$-ray and neck lymph node echogram results, the patient had presented with multiple lung metastasis at his 11th year follow-up. To our knowledge, this is the first case reported for distant metastases after an interval of more than 10 years disease-free. There is a possibility that the tumor had metastasized earlier, but the metastases was not recognized due to the tumor being asymptomatic and chest X-ray being insufficient for early diagnosis. Furthermore, the behavior of MCS as being slow growing and clinically asymptomatic may have delayed the diagnosis of the metastases. Distant metastases are highly resistance to radiotherapy and chemotherapy $[11,22]$. Thus, early diagnosis and resection of metastases is important for long-term prognosis. Given the history of our case, we recommend annual follow-up with detailed systematic examination, such as whole-body CT and RI in the case of MCS with local recurrence and lymph node metastasis.

Open Access This article is distributed under the terms of the Creative Commons Attribution Noncommercial License which permits any noncommercial use, distribution, and reproduction in any medium, provided the original author(s) and source are credited.

\section{References}

1. Abe S, Matsumoto Y, Fujita T (1997) Primary mucinous carcinoma of the skin. Plast Reconstr Surg 99:1160-1164 doi:10.1097/00006534-199704000-00040
2. Breiting L, Christensen L, Dahlstrom K, Breiting V, Winther JF (2008) Primary mucinous carcinoma of the skin: a populationbased study. Int J Dermatol 47:242-245 doi:10.1111/j.13654632.2008.03558.x

3. Kazakov DV, Suster S, LeBoit PE, Calonje E, Bisceglia M, Kutzner H, Rutten A, Mentzel T, Schaller J, Zelger B, Baltaci M, Leivo I, Rose C, Fukunaga M, Simpson RH, Yang Y, Carlson JA, Cavazza A, Hes O, Mukensnabl P, Vanecek T, Fidalgo A, Pizinger K, Michal M (2005) Mucinous carcinoma of the skin, primary, and secondary: a clinicopathologic study of 63 cases with emphasis on the morphologic spectrum of primary cutaneous forms: homologies with mucinous lesions in the breast. Am J Surg Pathol 29:764-782 doi:10.1097/01. pas.0000159104.02985.6b

4. Breiting L, Dahlstrom K, Christensen L, Winther JF, Breiting V (2007) Primary mucinous carcinoma of the skin. Am J Dermatopathol 29:595-596

5. Jih MH, Friedman PM, Kimyai-Asadi A, Goldberg LH (2005) A rare case of fatal primary cutaneous mucinous carcinoma of the scalp with multiple in-transit and pulmonary metastases. J Am Acad Dermatol 52:S76-S80 doi:10.1016/j.jaad.2004.06. 047

6. Reid-Nicholson M, Iyengar P, Friedlander MA, Lin O (2006) Fine needle aspiration biopsy of primary mucinous carcinoma of the skin: a case report. Acta Cytol 50:317-322

7. Snow SN, Reizner GT (1992) Mucinous eccrine carcinoma of the eyelid. Cancer 70:2099-2104 doi:10.1002/1097-0142(19921015) 70:8<2099::AID-CNCR2820700815>3.0.CO;2-C

8. Lennox B, Pearse AG, Richards HG (1952) Mucin-secreting tumours of the skin with special reference to the so-called mixed-salivary tumour of the skin and its relation to hidradenoma. J Pathol Bacteriol 64:865-880 doi:10.1002/path. 1700640418

9. Mendoza S, Helwig EB (1971) Mucinous (adenocystic) carcinoma of the skin. Arch Dermatol 103:68-78 doi:10.1001/archderm. 103.1.68

10. Wako M, Nishimaki K, Kawamura N, Harima N, Kubota T, Yoneda K, Manabe M, Ansai S (2003) Mucinous carcinoma of the skin with apocrine-type differentiation: immunohistochemical studies. Am J Dermatopathol 25:66-70 doi:10.1097/00000372200302000-00014

11. Weber PJ, Hevia O, Gretzula JC, Rabinovitz HC (1988) Primary mucinous carcinoma. J Dermatol Surg Oncol 14:170-172

12. Vodovnik A (2006) Primary mucinous carcinoma of the skin. J Cutan Pathol 33:61-62 doi:10.1111/j.0303-6987.2006.00441.x

13. Ortiz KJ, Gaughan MD, Bang RH, Padilla RS, Crooks LA (2002) A case of primary mucinous carcinoma of the scalp treated with mohs surgery. Dermatol Surg 28:751-754 (discussion 754). doi:10.1046/j.1524-4725.2002.02007.x

14. Hanby AM, McKee P, Jeffery M, Grayson W, Dublin E, Poulsom R, Maguire B (1998) Primary mucinous carcinomas of the skin express TFF1, TFF3, estrogen receptor, and progesterone receptors. Am J Surg Pathol 22:1125-1131 doi:10.1097/00000478199809000-00012

15. Breier F, Clabian M, Pokieser W, Feldmann R, Pelzl M, Kosak D, Volc-Platzer B, Kolbabek H, Gschnait F (2000) Primary mucinous carcinoma of the scalp. Dermatology 200:250-253 doi:10.1159/ 000018369

16. Warycha M, Kamino H, Mobini N, Hale EK (2006) Primary mucinous carcinoma with direct histopathologic evidence of lymphatic invasion. J Drugs Dermatol 5:655-658

17. Pilgrim JP, Kloss SG, Wolfish PS, Heng MC (1985) Primary mucinous carcinoma of the skin with metastases to the lymph 
nodes. Am J Dermatopathol 7:461-469 doi:10.1097/00000372198510000-00011

18. Santa-Cruz DJ, Meyers JH, Gnepp DR, Perez BM (1978) Primary mucinous carcinoma of the skin. Br J Dermatol 98:645-653 doi:10.1111/j.1365-2133.1978.tb03583.x

19. Tanaka A, Hatoko M, Kuwahara M, Tada H, Muramatsu T (2000) Recurrent mucinous carcinoma of the skin invading to the frontal skull base. Br J Dermatol 143:458-459
20. Rao KV, Tikku I, Kapur BM, Chopra P (1978) Invasive primary mucinous carcinoma of the skin. Int Surg 63:168-170

21. Martinez SR, Young SE (2005) Primary mucinous carcinoma of the skin: a review. Internet $\mathrm{J}$ Oncol 2

22. Friednash M, Golitz L, Bohlmeyer T (1997) Periorbital solitary nodule and multiple small papules in a 63-year-old women. Primary mucinous carcinoma (nodule) and syringom (papules). Arch Dermatol 133:1161-1164 